\title{
Validation of the primary care experiences survey developed with Indigenous patients with type 2 diabetes in Canada
}

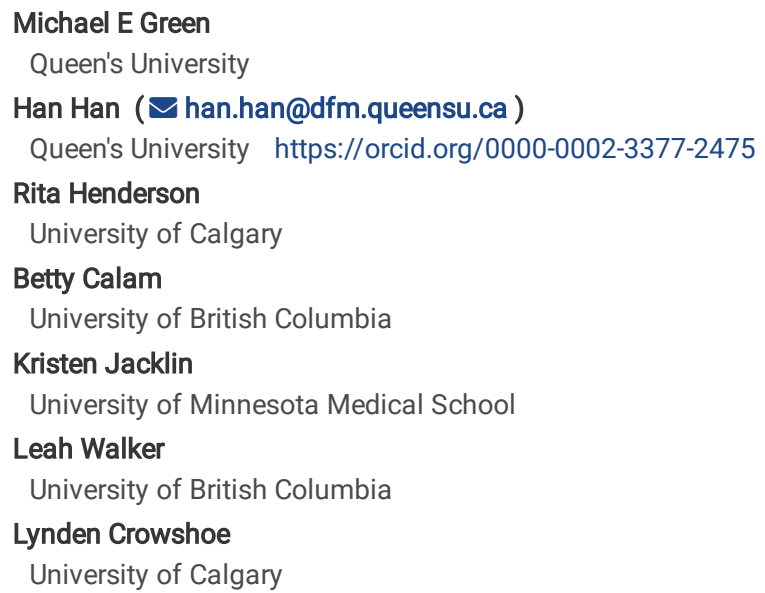




\section{Abstract}

Background Health disparities experienced among Indigenous populations in Canada arise from complex historical and social causes. Addressing health disparities requires a multi-sectoral approach, including measures for Indigenous patient healthcare experiences. The Canadian Institute for Health Information published Measuring Patient Experiences in Primary Health Care Survey to evaluate care experiences among general populations; it is not known whether this survey tool is appropriate to measure Indigenous people's experiences of healthcare. As part of a large research project known as Educating for Equity (E4E), we developed an Indigenous patient experiences with diabetes care survey from existing validated primary care assessment tools, adapting items to the domains of the E4E Care Framework that addresses social and cultural factors that impact Indigenous health. This study describes the development of this Indigenous patient experiences survey, assessing the tool's validity and reliability.

Method A consensus approach was used to establish the face validity of the survey and ease of completion. The survey was administered in three on- and offreserve practices in Northern Ontario during 2015 and 2016. In total, 154 completed surveys were collected for data analysis. Exploratory factor analysis was performed to assess the survey's structure. Internal consistency, item convergent validity and discriminant validity were assessed to determine internal reliability and correlation of items within each scale and between scales.

Results The Indigenous patient experiences survey consists of two sections: a patient demographic section of eight items and healthcare experience section of 36 items on Likert scales. Exploratory factor analysis identified seven main and sub-scales that align with the survey's conceptual domains. Two items were removed due to insufficient loading scores. All main and sub-scales obtained acceptable internal reliability (Cronbach's a: $0.7-0.957)$, item convergent validity (AVE: 0.4-0.7; CR: 0.78-0.99), and discriminant validity ( $\sqrt{ }$ AVE: 0.66-0.85).

Conclusion The Indigenous patient experiences survey maps out the construct concepts of the E4E Care Framework: provider-patient relationship, provider cultural competence and social sensitivity, patient diabetic-related psychosocial self-efficacy, and patient-centred continuity of care. Study results indicate this culturally-tailored instrument is reliable and valid for measuring primary care experiences of Indigenous patients with diabetes in Ontario, Canada.

\section{Methods}

\section{Participants}

Patients were recruited from one on-reserve and two off-reserve family medicine clinics located in Northern Ontario. Patients were eligible to participate in the survey if they were 18 years of age or above, had type 2 diabetes, self-identified as Indigenous, and saw the same family physician during the study time from September 2014 to April 2016.

\section{Survey administration and data collection}

Prior to a clinical appointment, the practice receptionist identified patients who were eligible to participate in the survey, informed them about the study, and asked if they were willing to participate in the patient survey. If a patient was interested, the receptionist would provide an information sheet outlining the purpose of the study and a consent form with instruction to sign if agreeable to participation. The receptionist collected the signed consent prior to the clinical appointment. Following the appointment, the patient was instructed to complete the survey. Onsite clinical support staff would provide assistance in reading and interpreting survey questions upon request. At the end of each day, the receptionist or office staff collected completed surveys and submitted them to the site research lead. All completed surveys were mailed via Express Post to a project team member $(\mathrm{HH})$ in Ontario.

\section{Data analysis}

Data analysis was based on the shorter version of the IPES (plus T2DM) that was administered in the second round. The first round responses to the 23 questions that were removed for the second round were not included.

The purpose of the validation was to assess congruence between the proposed conceptual scales for the IPES (plus T2DM) and the underlying structure of this survey identified by empirical results. Validation involved four steps:

(1) Exploratory factor analysis (EFA) was used to explore the survey's structure. Principal factor analysis was performed to identify the factor structure and observe if the survey items fell into the conceptual domains based on factor loadings.[34] Three criteria were used to determine retained items and factors. First, an item with loading above 0.35 , no secondary loading above 0.35 , and its communalities extraction score above 0.4 was considered for retaining. Communalities extraction score between 0-0.4 suggests that the variables may struggle to load significantly on any factor and indicates the candidate variable for removal after examination of the pattern matrix. Second, each factor had a minimum three retained items. Third, all retained items under each factor should share the same concept or construct. [34, 35]

(2) Internal consistency reliability analysis was performed to assess the internal consistency of items within each scale by Cronbach's coefficient alpha (a). Cronbach's coefficient alpha is based on the covariance among individual items within a scale and the number of items. It ranges from 0 (indicating no internal consistency reliability) to 1 (indicating full internal consistency reliability), where the minimum accepted Cronbach's coefficient alpha is cut at 0.7 . [34, ${ }^{36]}$ In addition, item-total correlation, which is the relationship between an item and its scale, was observed. If an item-total correlation is small, then this item is not considered to be measuring the construct that is measured by other items in the same scale. In this study, the cutoff for item-total correlation was 0.3 . ${ }^{[34]}$

(3) Item convergent validity and discriminant validity. were assessed to identify the correlation levels of each individual item with its conceptual scale and with other conceptual scales. Item convergent validity was observed by average variance extracted (AVE) and composite reliability (CR) ${ }^{[37-39]}$. AVE "reflects the 
overall amount of variance in the indicators accounted for by the latent construct". ${ }^{[38, p 612]}$ The threshold for AVE value is $0.5 .{ }^{[37,38]}$ CR estimates the extent to which a set of latent construct indicators share in their measurement of a construct, where the AVE is the amount of common variance among the latent construct indicators. ${ }^{[38]}$ The acceptable CR value is set at 0.5. ${ }^{[38]}$

Discriminant validity refers to the extent to which factors or constructs are distinct and uncorrelated. ${ }^{[38,39]}$ Discriminant validity can be determined by comparing the square root AVE of a latent construct and its correlations with other constructs. Discriminate validity is indicated if the square root AVE value of a construct is greater than the correlation values of this construct with other constructs. ${ }^{[39]}$

(4) Descriptive statistics were performed to identify participating patients' demographics, including gender, age, education, household income, and health status. As well, based on the validation results, descriptive statistics were performed on the retained items to describe the property of the revised IPES in terms of means, standard deviation, range, percentile, and skewness and kurtosis.

\section{Results}

\section{Participants' demographics}

Between rounds 1 and 2, a total of 154 participants completed the IPES (plus T2DM). They were on average 50 years of age, with $72.1 \%$ women. Over half of participants (52.6\%) were married or living with a partner, $23.9 \%$ were separated, divorced or widowed. Over half (52.6\%) had education up to high school, close to $41 \%$ had post-secondary education or some college level. Only $2.6 \%$ received university education. Close to $41 \%$ of participants had annual household incomes under $\$ 20,000$, around $14 \%$ of participants between $\$ 20,000$ and $\$ 40,000$, and $20 \%$ of participants between $\$ 40,000$ and $\$ 60,000$. About $17.6 \%$ of participants had an annual household income above $\$ 60,000$.

Although over half of the participants (54.6\%) self-rated their health condition from good (40.9\%), very good (11.7\%) to excellent (1.95\%), most participants reported living with one or more types of chronic disease: $64.9 \%$ had hypertension, $31.2 \%$ had depression and anxiety, $28.6 \%$ had arthritis, $22.7 \%$ had heart diseases, and $29.9 \%$ had other chronic conditions.

\section{Statistical validation results-Psychometric properties of the IPES (plus T2DM)}

\section{Exploratory Factor Analysis Results}

KMO value (0.876) and Bartlett's Test of Sphericity value $(\mathrm{p}=0.00)$ indicated that the data collected from the Indigenous patient experience survey were adequate for factor analysis. Principal component analysis was performed on the 36 survey items on Likert scales. Eight (8) factors that had Eigenvalues above 1.0 were extracted. However, the rotated (Promax with Kaiser Normalization) pattern matrix showed that two factors failed to obtain sufficient retained items (a minimum of three items with loading $>0.35$ ) under each. When the number of factor extraction was suppressed to six, one factor still did not have an adequate number of retained items. When the number of factors was suppressed to five for extraction, each factor obtained an adequate number of retained items. These five retained factors explained a total of $63.9 \%$ of the variance (see Table 3 ).

The pattern matrix in Table 3 illustrates the item loadings and factor structure; 34 out of 36 survey items were retained and loaded onto five factors. Items 29 and 31 had loadings lower than 0.35 , and their communalities extraction scores were below $0.4,{ }^{[34]}$ indicating that that they had very low variance explained by any factors and should be considered for removal from the survey.

The factor structure showed a close correspondence to the proposed conceptual domains and concepts of the IPES (plus T2DM) (see Table 4). Factor \#1 was loaded with 12 items that reflected two sub-scales of concepts: (a) interpersonal communication ( 9 items), including the provider giving enough time during visit, listening to the patient, eliciting patient concerns, expectations and preference for care, and explaining tests, treatment, and self-care; (b) doctor-patient relationships ( 3 items), including providing the patient with emotional support and having patient trust. Items 4 and 10 were related to discussion of care plan during office visit, and the factor loadings group them with the communication scale. Factor \#2 was loaded with six items on the concepts of patients with diabetes self-efficacy. Factor \#3 was loaded with eight items on two subscales of concepts: (a) holistic and continuing care (5 items), and (b) physician cultural sensitivity (3 items). Factor \#4 was loaded with four items on the concept of decision making. Factor \#5 was loaded with four items on the concepts of physician social sensitivity (discrimination). This indicates the validity of the construct structure embedded in IPES (plus T2DM).

Internal Reliability of the IPES (plus T2DM) Scales

Table 5 presents the results of internal reliability analysis of each scale and sub-scale and the descriptive results of survey items. Cronbach's alpha (a) and item-total correlation scores indicated internal reliability of each scale. The Cronbach's a of seven scales (including subscales) ranged from 0.7 to 0.9 , indicating that these scales had acceptable and strong internal consistency. The revised item-total correlation scores ranged from 0.31 to 0.85 , also indicating from acceptable to strong relationship between the items and their affiliated scales. The original scale of "Social Sensitivity (Discrimination)" had five items (25-29), one of which, item 29, showed very low internal consistency and weak relationship with the scale (Item-Total correlation =0.04). When item 29 was deleted, the Cronbach's a of the scale increased to 0.7 , and the revised item-total correlation scores of other items improved, ranging from 0.31 to 0.60 . Also, item 31 was weak in internal consistency and correlation with the scale "Diabetic Patient Self-Efficacy" (Item-Total Correlation =0.13); when this item was deleted, the Cronbach's a of this scale increased to 0.9 , and the revised item-total correlation scores of the other six items improved, ranging from 0.47 to 0.83 .

$\underline{\text { Item convergent validity and discriminant validity }}$ 
Table 6 presents the convergent validity and discriminant validity of the revised survey based on the factor loadings and Cronbach's a of each scale. All scales obtained high CR scores (0.78 0.99), indicating strong composite reliability within each scale. The AVE scores of four main scales - Interpersonal

Communication/Relationship, Decision Making, Social Sensitivity and Patient Self-Efficacy - were at and above 0.5 (range $0.5 \sim 0.7$ ). The AVE and CR sores of these four scales indicate from acceptable to good convergent validity of the items affiliating to their own scales. The AVE of the scale "Holistic Care and Cultural Competence" was slightly lower than 0.5 ; however, combining its strong CR score $(0.86)$, this scale might still have acceptable convergent validity.

In Table 6, the square root AVE value of each scale is higher than the correlation values with other scales, indicating that all five scales have discriminant validity. The convergent validity and discriminant validity of all five scales establish the construct validity of the revised IPES (plus T2DM) (34 items).

Descriptive Feature of the IPES (plus T2DM).

Table 7 presents the descriptive features of the IPDES after removing two items from the survey (item 29 and item 31). The mean distribution of 30 items (items 1-10, item 13, items 18-36) that were on 5-point Likert scales varied from 2.91 to 4.81 , tending to skew to the right (>3.0, except item 20 ). The mean distribution of four items (items 14-17) that were on 4-point Likert scales ranged from 2.94 to 3.22 , skewing to the right (>2.5). The mean distribution of two items (items 11 and 12) that were on a 3-point Likert scale was the same at 2.59, skewing to the right (>2.0).

The central tendency and dispersion of scale scores for seven main and sub-scales of the revised IPES (plus T2DM) are presented in Table 7. The observed mean and median values for each scale were close with slight difference (range: $-0.28 \sim 0.04$ ), indicating that the data were symmetrically distributed. All scales were right skewed (range: -2.276 -0.123), indicating distributions with more positive ratings on the IPES (plus T2DM). The Kurtosis values for five scales (Interpersonal Communication, Interpersonal Relationship, Decision Making, Holistic/Continuing Care, and Cultural Competence) are close to 0, ranging from -0.117 to 0.534 , indicating a close normality of data distribution on these scales. ${ }^{[40]}$ The Kurtosis values for Social Sensitivity (Discrimination) and Diabetes Patient Self-Efficacy are greater than 3, indicating non-normality of data distribution on these two scales. [40]

\section{Discussion}

The IPES (plus T2DM) adopted the scales and items from the CIHI's Measuring Patient Experiences in Primary Health Care Survey, used to measure the care experience of Canadian general populations, adding the Diabetes Empowerment Scale-Short Form (DES-SF) that has been validated to measure diabetes patients' self-management in the United States. Our EFA results identified five major scales with two sub-scales. The concepts of these scales and sub-scales were empirically consistent with the proposed conceptual domains. The internal consistency results show an acceptable internal consistency and reliability of each scale and item-scale correlation after eliminating two items (\#29 and \#31) from the survey. The convergent validity and discriminant validity results indicate acceptable construct validity of the revised IPES (plus T2DM). Descriptive statistics results indicate normal and close-to-normal distribution of participants' responses to each latent scale in the survey. In total, these psychometric features confirm that the scales and sub-scales used in our survey have adequate content validity, construct validity, internal consistency and reliability.

The development and validation of IPES (plus T2DM) partially answers the health-related Call for Actions of the Truth and Reconciliation Commission (TRC). [41] Call \#19 asks "to establish measurable goals to identify and close the gaps in health outcomes between Aboriginal and non-Aboriginal communities." Inclusion of Indigenous patients in performance measurement efforts in primary care generally and diabetes care more specifically requires the use of appropriate validated instruments. It should be noted that the IPES (plus T2DM) is not a new survey. The IPES part is developed from the CIHI's Measuring Patient Experiences in Primary Health Care Survey, is adapted to the E4E Care Framework, and is validated with Indigenous patient responses. By building on established questions and scales that are in use in the general population, we have been able to identify questions, scales, and sub-scales that are both valid and comparable to those commonly used in other populations. The results of this study indicate that the majority of CIHI's patient PHC experiences survey is appropriate to measure healthcare experiences of Indigenous patients in the areas of clinician-patient communication and relationships, clinicians' cultural competence and social sensitivity, patient-centred decision making, and holistic and continuing care. The validated IPES, which is aligned with existing measures for PHC for general populations, allows for comparison of experiences of Indigenous and non-Indigenous experiences with PHC and helps to identify specific gaps and care disparities in Indigenous healthcare services.

National and international researchers have identified disparities in Indigenous care and cultural and social determinants related to Indigenous health. ${ }^{[9-11,32,}$ ${ }^{33,42-44]}$ Efforts were made here to explore what to measure in Indigenous patient healthcare experiences, and how. ${ }^{[45]}$ The validated IPES (plus T2DM) is a contribution to this pool of knowledge. It has shown capable of capturing the experiences of Indigenous patients living with diabetes in Canada, and it can be adapted to measuring Indigenous patients living with other chronic diseases. For example, the "Diabetes Patient Self-Efficacy" scale can be replaced with a validated measure tool for any other chronic condition. The IPES (plus T2DM) can also be attuned to specifics within Indigenous contexts, such as connecting to traditional healing and treatment as are mentioned in TRC Calls \#21 and \#22. ${ }^{[41]}$ This tool can help physicians or potentially wider clinical efforts to be meaningfully responsive to Indigenous patient needs and priorities and bring quality of care for Indigenous populations.

\section{Conclusions}

The IPES (plus T2DM) was culturally tailored to the healthcare experience of Canadian Indigenous populations. It captures Indigenous experiences in physician-patient relationships, physician cultural competence and social sensitivity, patient-centred decision-making, continuity of care, and psychosocial self-efficacy among patients with diabetes or chronic diseases. The results of this study show that the revised IPES (plus T2DM) is a valid tool for measuring healthcare experiences of Indigenous patients with type 2 diabetes in Northern Ontario. We hope this survey tool has potential applicability to measuring Indigenous patient experiences with other chronic diseases beyond T2DM.

Page $4 / 12$ 


\section{Abbreviations}

E4E

Educating for Equity

$\mathrm{PHC}$

primary health care

$\mathrm{ClHI}$

Canadian Institute for Health Information

IPES

Indigenous patient experiences survey

DSE-SF

Diabetes Self-Efficacy Short Form

EFA

exploratory factor analysis

KMO

Kaiser-Meyer-Olkin (statistic)

AVE

average variance extracted

$\mathrm{CR}$

composite reliability

\section{Declarations}

Ethics approval and consent to participate

All study procedures were approved by the ethnic review boards of the universities of the project team members: Queen's University Health Sciences Research Ethics Board (EPID-439-13); University of Calgary Conjoint Faculties Research Ethics Board; Laurentian University Research Ethics Board, University of British Columbia Office of Research Ethics. Informed consent was obtained from the patients who participated in the patient experience surveys.

Consent for publication

Not applicable

Availability of data and materials

Data and materials are securely stored in Centre for Studies in Primary Care, Department of Family Medicine, Queen's University at Kingston, Ontario, Canada. Inquiry for data results should contact corresponding author via email at han.han@dfm.queensu.ca.

Competing Interests

No financial and non-financial competing interests are declared.

Funding

The Canadian Institutes of Health Research funded this study through the International Collaborative Indigenous Health Research Partnership grant (\#IDP103986, grant no. RT735835), in partnership with the Health Research Council of New Zealand, and the Australian Government National Health and Medical Research Council. The funder had no role in the research.

Authors' contributions

M.G and L.C. led methodological design, survey development and administration, and manuscript development. M.G. and H.H. led data collection and analysis and contributed to manuscript development. R.H., B.C., K.J., L.W assisted manuscript development and review. M.G. is the guarantor of this article, had full access to the complete data set of the study, and is responsible for the accuracy of data and data analysis. All authors have read and approved the manuscript.

Acknowledgements

We express our gratitude to Emily Johnston who assisted with survey data collection. We also thank the clinical practices in Northern Ontario and their staff who assisted us with survey distribution, administration and collection.

\section{References}

1. Young TK, Reading J, Elias B, O'Neil JD. Type 2 dabetes mellitus in Canada's First Nations: status of an epidemic in progress. CMAJ. 2000;163(5):561-6.

2. Dannenbaum D, Kuzmina E, Lejeune P, et al. Prevalence of diabetes-related complications in First Nations communities in Northern Quebec (Eeyou Istchee), Canada. Can J Diabetes. 2008;32:46-52. https://doi.org/10.1016/S1499-2671(08)21010-5. 
3. Greenwood M, de Leeuw S, Lindsay NM, et al. Determinants of indigenous peoples' health in Canada: beyond the social. Toronto: Canadian Scholars' Press; 2015.

4. Harris SB, Nagshbandi M, Bhattacharyya O, Hanley AJ, Esler JG, Zinman B. Major gaps in diabetes clinical care among Canada's First Nations: results of the CIRCLE study. Diabetes Res Clin Pract. 2011;92(2):272-9. https://doi.org/10.1016/j.diabres.2011.02.006.

5. Adelson N. The embodiment of inequity: health disparities in Aboriginal Canada. Can J Public Health. 2005;96:45-61.

https://doi.org/10.1007/BF03403702.

6. King M, Smith A, Gracey M. Indigenous health part 2: the underlying causes of the health gap. Lancet. 2009;374:76-85. https://doi.org/10.1016/s01406736(09)60872-8.

7. Marmot M, Friel S, Bell R, et al. Closing the gap in a generation: health equity through action on the social determinants of health. Lancet. 2008;372:1661-9. https://doi.org/10.1016/s0140-6736(08)61690-6.

8. Browne AJ, Varcoe CM, Wong ST, et al. Closing the health equity gap: evidence based strategies for primary health care organizations. Int $\mathrm{J}$ Equity Health. 2012;11:59. https://doi.org/10.1186/1475-9276-11-59.

9. Jacklin K, Ly A, Calam B, Green M, Walker L, Crowshoe L. An innovative Sequential Focus Group method for investigating diabetes care experiences with Indigenous peoples in Canada. Int J Qual Methods 2016;1-12. https://doi.org/10.1177/1609406916674965.

10. Jacklin KM, Henderson RI, Green ME, Walker LM, Calam B, Crowshoe LJ. Health care experiences of Indigenous people living with type 2 diabetes in Canada. CMAJ. 2017;189(3):E106-12. https://doi.org/10.1503/cmaj.161098.

11. Crowshoe LL, Henderson RI, Green ME, Jacklin KM, Walker LM, Calam B. Exploring Canadian physicians' experiences with diabetes care for Indigenous patients. Can J Diabetes. 2018;42(3):281-8. https://doi.org/10.1016/j.jcjd.2017.06.012.

12. Stewart AL, Hays RD, Ware JE. Methods of constructing health measures. In: Stewart AL, Ware JE, editors. Measuring functioning and well-being: the medical outcome study approach. Durham: Duke University Press; 1992. pp. 67-85.

13. Stewart AL, Napolies-Springer A, Perez-Stable EJ, et al. Interpersonal processes of care in diverse populations. Milbank Q. 1999;77(3):305-39.

14. Stewart AL, Napoles-Springer AM, Gregorich SE, Stantoyo-Olsson J. Interpersonal process of care survey: patient-reported measures for diverse groups. Health Serv Res. 2007;42(3):1235-56. https://doi.org/10.1111/j.1475-6773.2006.00637.x.

15. Blanchard J, Lurie N. "R-E-S-P-E-C-T". Patient reports of disrespect in health care setting and its impact on care. J Fam Pract. 2004;53(9):721-30.

16. Hargraves JL, Hays RD, Cleary PD. Pcyhometric properties of the consumer assessment of health plans study (CAHPS) 2.0 Adult Core Survey. Health Serv Res. 2003;38(6):1509-27. https://doi.org/10.1111/j.1475-6773.2003.00190.x.

17. Gallagher TJ, Hartung PJ, Gregory SW Jr. Assessment of a measure of relational communication for doctor-patient interactions. Patient Educ Couns. 2001;45(3):211-8. https://doi.org/10.1016/s0738-3991(01)00126-4.

18. Safran DG, Kosinski M, Tarlov AR, Rogers WH, Taira DA, Lieberman N, Ware JE. The primary care assessment survey. Test of data quality and measurement performance. Med Care. 1998;36(5):728-39. https://doi.org/10.1097/00005650-199805000-00012.

19. Flock SA. Measuring attributes of primary care: development of a new instrument. J Fam Pract. 1997;45(1):64-74.

20. Ramsay J, Campbell JL, Schroter S, Green J, Roland M. The General Practice Assessment Survey (GPAS): tests of data quality and measurement properties. Fam Pract. 2000;17:372-9. https://doi.org/10.1093/fampra/17.5.372.

21. Glasgow RE, Toobert DJ, Barrera M Jr, Strycker LA. The Chronic Illness Resources Survey: cross-validation and sensitivity to intervention. Health Edu Res. 2005;20(4):402-9.

22. Hays RD, Davies AR, Ware JE. Scoring the medical outcomes study short-form patient satisfaction questionnaire: PSQ-III. MOS Memorandum. https://www.rand.org/content/dam/rand/www/external/health/surveys_tools/psq/psq3_scoring.pdf. Accessed 20 Jun 2017.

23. Marhsall GN, Hays RD. The Patient Satisfaction Questionnaire-Short Form (QSQ-18). Santa Monica, CA: Rand. 1994.

https://www.rand.org/content/dam/rand/pubs/papers/2006/P7865.pdf. Accessed 20 Jun 2017.

24. Anderson RM, Fitzgerald JT, Gruppen LD, Funnell MM, Oh MS: The diabetes empowerment scale-short form (DES-SF). Diabetes Care. 2003, 26(5):1641-

1642. https://doi.org/10.2337/diacare.26.5.1641-a

25. Wong ST, Haggerty J. Measuring patient experiences in primary health care: a review and classification of items and scales used in publicly-available questionnaires. University of British Columbia, BC; May 2013. http://chspr.ubc.ca. Accessed 20 Jun 2017

26. Haggerty JL, Burge F, Beaulieu MD, Pineault R, Beaulieu C, Levesque JF, Santor D. Validation of instruments to evaluate primary healthcare from patient perspective: overview of the method. Healthcare Policy. 2011;7(special):31-49. https://doi.org/10.12927/hcpol.2011.22691.

27. Haggerty J, Roberge D, Freeman GK, Beaulieu C, Bréton M. Validation of a generic measure of continuity of care: when patients encounter several clinicians. Ann Fam Med. 2011;10(5):443-51. https://doi.org/10.1370/afm.1378.

28. Haggerty J, Lévesque J-F, Santor DA, Burge F, Beaulieu C, Bouharaoui F, Beaulieu M-D, Pineault R. Accessibility from the patient perspective: comparison of primary healthcare evaluation instruments. Healthcare Policy. 2011;7(Special Issue):94-107. https://doi.org/10.12927/hcpol.2011.22635.

29. Haggerty J, Bouharaoui F, Santor D. Differential item functioning in primary healthcare evaluation instruments by French/ English version, educational level and urban/rural location. Healthcare Policy. 2011;7(Special):19. https://doi.org/10.12927/hcpol.2011.22692.

30. ClHI. Experience with primary Health care in Canada. 2009. https://secure.cihi.ca/estore/productSeries.htm?pc=PCC482. Accessed 28 Oct 2014.

31. CIHI. Measuring Patient Experiences in Primary Health Care Survey. https://www.cihi.ca/sites/default/files/info_phc_patient_en.pdf. Accessed 5 Jun 2014.

32. Crowshoe L, Henderson R, Jacklin K, Calam B, Walker L, Green ME. Educating for equity care framework: Addressing social barriers of Indigenous patients with type 2 diabetes. Can Fam Physician. 2019;65:25-33. https://www.cfp.ca/content/65/1/25.long.

33. Crowshoe L, Han H, Calam B, Henderson R, Jacklin K, Walker L, Green ME. Impacts of Educating for Equity workshop on addressing social barriers of type 2 diabetes with Indigenous patients. J Contin Educ Health Prof. 2018;38(1):49-59. https://doi.org/10.1097/CEH.0000000000000188.

34. Costello AB, Osborne JW. Best practices in exploratory factor analysis: four recommendations for getting the most from your analysis. Practical Assessment, Research \& Evaluation. 2005;10(7). http://pareonline.net/getvn.asp?v=10\&n=7. Accessed 20 Mar 2017. 
35. Shi L, Starfield B, Xu J. Validating the adult primary care assessment tool. J Fam pract. 2001;50(2):161-175. https://www.jhsph.edu/research/centersand-institutes/johns-hopkins-primary-care-policy-center/PCAT\%20pubs/Shi\%202001.pdf. Accessed 22 Mar 2017.

36. Terwee CB, Bot SDM, de Boer MR, van der Windt DAWM, Knol DL, Dekker J, Bouter LM, de Vet HCW. Quality criteria were proposed for measurement properties of health status questionnaires. J Clin Epidemiol. 2007;60:34-42. https://doi.org/10.1016/j.jclinepi.2006.03.012.

37. Fornell C, Larcker DF. Evaluating structural equation models with unobservable variables and measurement error. J Marketing Res 1981;39-50.

https://doi.org/10.1177/002224378101800104.

38. Hair JF, Anderson RE, Tatham RL, Black WC. Multivariate data analysis. 5th ed. Upper Saddle River: Prentice-Hall, Inc.; 1998.

39. Hair JF, Black WC, Babin BJ, Anderson RE, Tatham RL. Multivariate Data Analysis. 6th ed. Upper Saddle River: Prentice-Hall International, Inc.; 2006.

40. Trochim WM, Donnelly JP. (2006). The research methods knowledge base, 3rd ed. Cincinnati, OH: Atomic Dog; 2006.

41. Truth and Reconciliation Commission of Canada. Calls to Action. 2015.

https://static1.squarespace.com/static/5ac510114611a0bcce082fac/t/5b92b141f950b758a9a5b2f2/1536340329039/TRC+Calls+to+Action+Pocket+bookle Accessed 20 Dec 2018.

42. Richardson L, Murphy T Bringing reconciliation to healthcare in Canada. HealthCareCAN. April 2018. http://www.healthcarecan.ca/wpcontent/themes/camyno/assets/document/Reports/2018/HCC/EN/TRCC_EN.pdf. Accessed 10 Jan 2019.

43. Goodman A, Fleming K, Markwick N, Morrison T, Lagimodiere L, Kerr T. "They treated me like crap and I know it was because I was Native": The healthcare experiences of Aboriginal people living in Vancouver's inner city. Soc Sci Med. 2017;178:87-94. https://doi.org/10.1016/j.socscimed.2017.01.053.

44. Davy C, Harfield S, McArthur A, Munn Z, Brown A. 2016. Access to primary health care services for Indigenous peoples: A framework synthesis. Int J Equity Health. 2016; 15:163. https://doi.org/10.1186/s12939-016-0450-5.

45. Green M, Anderson K, Griffiths K, Garvey G, Cunningham J. Understanding Indigenous Australians' experiences of cancer care: stakeholders' view on what to measure and how to measure it. BMC Health Serv Res. 2018;18:982. https://doi.org/10.1186/s12913-018-3780-8.

\section{Tables}

Table 1. Conceptual domains for measuring Indigenous patient experiences with diabetes care

\begin{tabular}{|c|c|}
\hline Proposed Conceptual Domains & Concepts \\
\hline Physician-patient communication & $\begin{array}{l}\text { Gives enough time to explain diagnosis, testing results, medication, process of care, and self-care; find out patient's problems, concerns, and } \\
\text { expectations }\end{array}$ \\
\hline Physician-patient relations & Exhibits friendliness, respectfulness, trust, emotional support \\
\hline Decision making & Responds to patient preference to treatment; considers patient ability to comply with recommendations \\
\hline Holistic and continuous care & Sustains continuing/longitudinal provider-patient relations; knows about patient regarding medical history, family, life and work, and values. \\
\hline Physician's cultural competence & Accommodates patients' limit in English language, understands and respects their traditional medicine and healing approach \\
\hline $\begin{array}{l}\text { Physician's social sensitivity } \\
\text { (discrimination) }\end{array}$ & Is sensitive to discrimination related to race/ethnicity, income, education, and life styles \\
\hline Diabetes self-empowerment & Diabetic patient's psychosocial self-efficacy to manage chronic conditions \\
\hline
\end{tabular}

Table 2 Indigenous participants' demographic information 


\begin{tabular}{|c|c|}
\hline \multicolumn{2}{|l|}{ Patients $(n=154)$} \\
\hline Age mean (SD) & $50.08(12.80)$ \\
\hline Gender (female) $n(\%)$ & $111(72.1 \%)$ \\
\hline \multicolumn{2}{|l|}{ Marital status $n(\%)$} \\
\hline Married/ living with a partner & $81(52.6 \%)$ \\
\hline Single/never married & $33(21.4 \%)$ \\
\hline Separated/Divorced & $28(18.1 \%)$ \\
\hline Widowed & $9(5.8 \%)$ \\
\hline Missing & $3(2.0 \%)$ \\
\hline \multicolumn{2}{|l|}{ Education $n(\%)$} \\
\hline high school or less & $81(52.6 \%)$ \\
\hline College, post-secondary program & $63(40.9 \%)$ \\
\hline Bachelor's degree & $4(2.6 \%)$ \\
\hline Missing & $6(3.9 \%)$ \\
\hline \multicolumn{2}{|l|}{ Household annual income } \\
\hline$<20,000$ & $63(40.9 \%)$ \\
\hline $20,000-40,000$ & $22(14.3 \%)$ \\
\hline $40,000-60,000$ & $31(20.1 \%)$ \\
\hline $60,000-80,000$ & $9(5.8 \%)$ \\
\hline $80,000-100,000$ & $13(8.5 \%)$ \\
\hline$>\$ 100,000$ & $5(3.3 \%)$ \\
\hline Missing & $11(7.1 \%)$ \\
\hline \multicolumn{2}{|c|}{ Self-rated health condition in the last year $n(\%)$} \\
\hline Excellent & $3(1.95 \%)$ \\
\hline Very good & $18(11.7 \%)$ \\
\hline Good & $63(40.9 \%)$ \\
\hline Fair & $49(31.8 \%)$ \\
\hline Poor & $20(13.0 \%)$ \\
\hline Missing & $1(0.65 \%)$ \\
\hline \multicolumn{2}{|l|}{ Chronic conditions $n(\%)$} \\
\hline HBP/Hypertension & $100(64.9 \%)$ \\
\hline Depression/Anxiety & $48(31.2 \%)$ \\
\hline Arthritis & $44(28.6 \%)$ \\
\hline Heart disease & $35(22.7 \%)$ \\
\hline Other conditions & $46(29.9)$ \\
\hline
\end{tabular}

Table 3 Pattern matrix of IDPES (plus T2DM) with factor loadings and communalities extraction scores 


\begin{tabular}{|c|c|c|c|c|c|c|c|}
\hline \multirow[b]{2}{*}{ Survey Items } & \multirow[b]{2}{*}{ Scale of Concepts } & \multicolumn{5}{|c|}{ Factors } & \multirow{2}{*}{$\begin{array}{l}\text { Communalities } \\
\text { Extraction }\end{array}$} \\
\hline & & 1 & 2 & 3 & 4 & 5 & \\
\hline 1.Today, the a mount of time that doctor gave you & Communication [Time] & .710 & & & & & 607 \\
\hline 2.Today, the way your doctor listened to you & Communication [Listen] & .816 & & & & & .780 \\
\hline 3.Today, your doctor explained tests and treatments & Communication [Explain] & .882 & & & & & .772 \\
\hline 4. Today, your doctor involved you in decisions about your care & Communication [Discussion] & .778 & & & & & 664 \\
\hline 5.Today, your doctor found out your concerns & Communication [Elicit concerns] & .769 & & & & & .704 \\
\hline 6. Today, your doctor let you say what your thought was important & Communication [Elicit concerns] & .860 & & & & & .801 \\
\hline 7. your doctor took your health concerns very seriously & Communication [Elicit concerns] & .846 & & & & & .686 \\
\hline $\begin{array}{l}\text { 9. Today, your doctor gave clear instructions about symptoms to watch for and when to seek further } \\
\text { care/treatment }\end{array}$ & Communication [Explain] & .838 & & & & & .627 \\
\hline 10. Today, your doctor discuss with you your main goals/ priorities in caring for your condition & Communication [Discussion] & .835 & & & & & .755 \\
\hline 8. Your doctor concerned about your feelings & Interpersonal relation [Emotional support] & .856 & & & & & 813 \\
\hline 11. You have confidence in the doctor you saw or spoke to & Interpersonal support [Trust] & .821 & & & & & .731 \\
\hline 12. You have trust in the doctor you saw or spoke to & Interpersonal support [Trust] & .836 & & & & & 737 \\
\hline 14. You and your doctor worked out a treatment plan together & Decision making & & & & .770 & & .684 \\
\hline 15. Your doctor asked you questions about your daily activities before deciding a treatment plan & Decision making & & & & .794 & & .686 \\
\hline 16. your doctor asked if you felt you could do the recommended treatment plan & Decision making & & & & .871 & & .799 \\
\hline 17. Your doctor asked you what treatment you would prefer & Decision making & & & & .763 & & .661 \\
\hline 13. You were taken care of by the same doctor & Holistic/continuity care & & & .674 & & & .594 \\
\hline 18. Your doctor/nurse seem to know about your whole me dical history & Holistic/ continuity care & & & .836 & & & .644 \\
\hline 19. your doctor/nurse seem to know about what worries you most about your health & Holistic/continuity care & & & .818 & & & .699 \\
\hline 20. your doctor/nurse seem to know about your responsibilities at work/home & Holistic/ continuity care & & & .799 & & & .739 \\
\hline 21. your doctor know what is important/meaningful to you in your life & Holistic/continuity care & & & .614 & & & .508 \\
\hline 22. You would recommend your family doctor to someone who does not speak English very well & Cultural competence [Culture] & & & .518 & & & .479 \\
\hline 23. You would recommend your family doctor to a friend or relative & Cultural competence [Culture] & & & .498 & & & .532 \\
\hline $\begin{array}{l}\text { 24. You would recommend your family doctor to someone who uses traditional/folk medicine or has } \\
\text { special beliefs about healthcare }\end{array}$ & Cultural competence [Culture] & & & 428 & & & .427 \\
\hline 25. Your doctor paid less attention to you because of your race/ethnicity & Social sensitivity [race/ethnic] & & & & & .707 & .630 \\
\hline 26. you felt discriminated against because of your race or ethnicity & Social sensitivity [race/ethnic] & & & & & .724 & .588 \\
\hline 27. Your doctor made assumptions about your level of education & Social sensitivity [education] & & & & & .748 & .551 \\
\hline 28. Your doctor made assumptions about your income & Social sensitivity [Income] & & & & & .549 & .353 \\
\hline 29. Your doctor made assumptions about your use of alcohol/drugs & Social sensitivity [alcohol/drug] & & & & & & .076 \\
\hline 30. you know the positive ways you cope with diabetes-related stress & Self-efficacy [DES-cope with stress] & .416 & .507 & & & & .478 \\
\hline $\begin{array}{l}\text { 31. You are confident you can maintain the changes in health habits, like diet/exercise, even during } \\
\text { times of stress }\end{array}$ & $\begin{array}{l}\text { Self-efficacy [maintain changes during } \\
\text { stress] }\end{array}$ & & & & & & .152 \\
\hline 32. You know enough about yourself as a person to make diabetes care choice right for you & Self-efficacy [DES- make care choice] & & .854 & & & & .743 \\
\hline 33. You can ask for support for caring for your diabetes when you need it & Self-efficacy [DES- ask for support] & & .864 & & & & .735 \\
\hline 34. You are able to turn your diabetes goals into a workable plan & $\begin{array}{l}\text { Self-efficacy [DES-turn diabetes goal into } \\
\text { workable plan] }\end{array}$ & & .919 & & & & .851 \\
\hline 35. You can try out different ways of overcoming barriers to your diabetes goals & Self-efficacy [DES- overcome barriers ] & & .943 & & & & .880 \\
\hline 36. You know what helps you stay motivated to care for your diabetes & Self-efficacy [DES- stay motivated] & & .927 & & & & .847 \\
\hline & Eigenvalues & 12.81 & 4.49 & 2.18 & 2.12 & 1.40 & \\
\hline & Variance (\%) & 35.60 & 12.48 & 6.07 & 5.90 & 3.88 & \\
\hline & Accumulated variance (\%) & 35.60 & 48.08 & 54.15 & 60.05 & 63.93 & \\
\hline
\end{tabular}




\begin{tabular}{|c|c|c|}
\hline $\begin{array}{l}\text { Proposed Conceptual } \\
\text { Domains }\end{array}$ & Concepts & $\begin{array}{l}\text { Empirical Structure of Survey-Scales } \\
\text { and Sub-Scales }\end{array}$ \\
\hline $\begin{array}{l}\text { Physician-patient } \\
\text { communication }\end{array}$ & $\begin{array}{l}\text { Gives enough time to explain diagnosis, testing } \\
\text { results, medication, process of care, and self- } \\
\text { care; find out patient's problems, concerns, and } \\
\text { expectations }\end{array}$ & \multirow{2}{*}{$\begin{array}{l}\text { Physician-patient communication and } \\
\text { relationship (12 items) } \\
\text { a. Interpersonal communication ( } 9 \\
\text { items) } \\
\text { b. Interpersonal relationship ( } 3 \text { items) }\end{array}$} \\
\hline Physician-patient relations & $\begin{array}{l}\text { Exhibits friendliness, respectfulness, trust, } \\
\text { emotional support }\end{array}$ & \\
\hline $\begin{array}{l}\text { Patient-centred decision } \\
\text { making }\end{array}$ & $\begin{array}{l}\text { Responds to patient preference to treatment; } \\
\text { considers patient ability to comply with } \\
\text { recommendations }\end{array}$ & Patient-centred decision making ( 4 items) \\
\hline Holistic and continuous care & $\begin{array}{l}\text { Sustains continuing/longitudinal provider- } \\
\text { patient relations; knows about patient regarding } \\
\text { medical history, family, life and work, and } \\
\text { values }\end{array}$ & \multirow{2}{*}{$\begin{array}{l}\text { Holistic and continuing care with cultural } \\
\text { competence ( } 8 \text { items) } \\
\text { a. Holistic/continuous care ( } 5 \text { items) } \\
\text { b. Cultural competence ( } 3 \text { items) }\end{array}$} \\
\hline $\begin{array}{l}\text { Physician's cultural } \\
\text { competence }\end{array}$ & $\begin{array}{l}\text { Accommodates patients' limit in English } \\
\text { language, understand and respect their } \\
\text { traditional medicine and healing approach }\end{array}$ & \\
\hline $\begin{array}{l}\text { Physician's social sensitivity } \\
\text { (discrimination) }\end{array}$ & $\begin{array}{l}\text { Is sensitive to discrimination related to } \\
\text { race/ethnicity, income, education, life style }\end{array}$ & Social sensitivity (discrimination) (4 items) \\
\hline Diabetes patient self-efficacy & $\begin{array}{l}\text { Diabetes patient's psychosocial self-efficacy to } \\
\text { manage their chronic conditions }\end{array}$ & Diabetes patient self-efficacy ( 6 items) \\
\hline
\end{tabular}

Table 5 Internal consistency and reliability of the Indigenous diabetic patient experience scales 


\begin{tabular}{|c|c|c|c|c|c|c|c|c|}
\hline \multirow{4}{*}{$\begin{array}{l}\text { Scales and Items } \\
\begin{array}{l}1.1 \text { Interpersonal communication } \\
\text { Likert Scales: } 1-5 \text { ( } 1=\text { very poor/not at all, } 5=\text { very good/yes, completely) }\end{array}\end{array}$} & \multicolumn{3}{|c|}{ Reliability Statistics } & \multicolumn{3}{|c|}{ Item-Total Statistics } & \multicolumn{2}{|c|}{$\begin{array}{l}\text { Descriptive } \\
\text { statistics }\end{array}$} \\
\hline & Cronbach's & Items & Valid & \multirow{3}{*}{$\begin{array}{c}\text { Cronbach's } \alpha \text { if Item } \\
\text { deleted }\end{array}$} & \multirow{3}{*}{$\begin{array}{c}\text { Original } \\
\text { Item-Total Correlation }\end{array}$} & \multirow{3}{*}{$\begin{array}{l}\text { Revised Item-Total } \\
\text { Correlation }\end{array}$} & \multirow[t]{3}{*}{ Mean } & \multirow[t]{3}{*}{ SD } \\
\hline & $\alpha$ & $\mathrm{N}$ & cases & & & & & \\
\hline & 0.9 & 9 & 143 & & & & & \\
\hline \multicolumn{4}{|l|}{ (1) The amount of time your doctor gave you } & .939 & .74 & .74 & 4.08 & .876 \\
\hline \multicolumn{4}{|l|}{ (2) The way your doctor listened to you during the visit } & .933 & .85 & .85 & 4.21 & .871 \\
\hline \multicolumn{4}{|l|}{ (3) Your doctor's explanations of tests and treatments } & .934 & .83 & .83 & 4.25 & .835 \\
\hline \multicolumn{4}{|l|}{ (4) The way your doctor involved you in decisions about your care } & .938 & .77 & .77 & 4.18 & .810 \\
\hline \multicolumn{4}{|l|}{ (5) Your doctor found out your concerns } & .935 & .81 & .81 & 4.12 & .876 \\
\hline \multicolumn{4}{|l|}{\begin{tabular}{|l} 
(6) Your doctor let you say what you thought was important \\
\end{tabular}} & .935 & .82 & .82 & 4.23 & .932 \\
\hline \multicolumn{4}{|l|}{ (7) Your doctor took your health concerns very seriously } & .939 & .75 & .75 & 4.35 & .898 \\
\hline (9) Your doctor gave you clear instructions about symptoms to watch for & & & & .943 & .68 & .68 & 4.29 & .948 \\
\hline (10) Your doctor discussed with you your main goals/priorities in caring for y & your condition & & & .936 & .80 & .80 & 4.36 & .851 \\
\hline 1.2 Interpersonal relationship & Cronbach's & Items & Valid & Cronbach's $\alpha$ if Item & Original & Revised Item-Total & Mean & $\mathrm{SD}$ \\
\hline Likert scales: Q8: 1-5 (1=not at all, 5=yes, completely); Q11-12: 1-3 (1=not & $\alpha$ & $\mathrm{N}$ & cases & deleted & Item-Total Correlation & Correlation & & \\
\hline & 0.9 & 3 & 150 & & & & & \\
\hline (8) Your doctor was concerned about your feelings & & & & .899 & .72 & .72 & 4.33 & .916 \\
\hline (11) You have confidence in the doctor you saw or spoke to & & & & .764 & .83 & .83 & 2.59 & .603 \\
\hline (12) You have trust in the doctor you saw or spoke to & & & & .794 & .78 & .78 & 2.59 & .637 \\
\hline 2. Patient-centred decision making & Cronbach's & Items & Valid & Cronbach's $\alpha$ if Item & Original Item-Total & Revised Item-Total & Mean & SD \\
\hline Likert Scales: 1-4 ( $1=\mathrm{I}$ don't receive any treatment, $4=$ Yes, often) & $\alpha$ & $\mathrm{N}$ & cases & deleted & Correlation & Correlation & & \\
\hline & 0.9 & 4 & 146 & & & & & \\
\hline (14) You and your doctor worked out a treatment plan together & & & & .802 & .69 & .69 & 3.22 & .792 \\
\hline (15) Your doctor asked you questions about your daily activities before decidi & ing a treatme & nt plan & & .791 & .72 & .72 & 3.21 & .807 \\
\hline (16) Your doctor asked if you felt you could do the recommended treatment $\mathrm{p}$ & lan & & & .767 & .77 & .77 & 3.18 & .836 \\
\hline (17) Your doctor ask you what treatment you would prefer & & & & .857 & .58 & .58 & 2.94 & .934 \\
\hline 3.1 Holistic/continuing care & Cronbach's & Items & Valid & Cronbach's $\alpha$ if Item & Original Item-Total & Revised Item-Total & Mean & SD \\
\hline Likert scales: 1 -5 ( 1 =never/hardly at all, 5=always/totally) & $\alpha$ & $\mathrm{N}$ & cases & Deleted & Correlation & Correlation & & \\
\hline & 0.9 & 5 & 146 & & & & & \\
\hline (13) You were taken care of by the same doctor in this clinic & & & & .855 & .60 & .60 & 3.54 & 1.429 \\
\hline (18) Your doctor/nurse seemed to know about your whole medical history & & & & .836 & .67 & .67 & 3.44 & 1.334 \\
\hline (19) Your doctor/nurse seemed to know about what worries you most about yo & our health & & & .818 & .74 & .74 & 3.23 & 1.296 \\
\hline (20) Your doctor/nurse seemed to know about your responsibilities at work or & r home & & & .812 & .76 & .76 & 2.91 & 1.349 \\
\hline (21) Your doctor know about what is important or meaningful to you in your li & & & & .842 & .64 & .64 & 3.15 & 1.361 \\
\hline 3.2 Cultural competence & Cronbach's & Items & Valid & Cronbach's $\alpha$ if Item & Original & Revised Item-Total & Mean & $\mathrm{SD}$ \\
\hline Likert scales: 1-5 ( 1 =definitely not, $5=$ definitely) & $\alpha$ & $\mathrm{N}$ & cases & Deleted & Item-Total Correlation & Correlation & & \\
\hline & 0.8 & 3 & 146 & & & & & \\
\hline (22) You would recommend your family doctor to someone who does not spea & ak English ver & ry well & & .699 & .64 & .64 & 3.54 & 1.370 \\
\hline (23) You would recommend your family doctor to a friend or relative & & & & .649 & .71 & .71 & 4.13 & 1.128 \\
\hline (24) You would recommend your family doctor to someone who uses tradition & al or folk med & dicine & & .792 & .56 & .56 & 3.49 & 1.351 \\
\hline 1. Social sensitivity (Discrimination) & Cronbach's & Items & Valid & Cronbach's $\alpha$ if Item & Original & Revised Item-Total & Mean & SD \\
\hline Likert scales: $1-5$ ( $1=$ always, $5=$ none of the time $)$ & $\alpha$ & $\mathrm{N}$ & cases & Deleted & Item-Total Correlation & Correlation & & \\
\hline & 0.7 & 4 & 150 & & & & & \\
\hline (25) Your doctor paid less attention to you because of your race or ethnicity & & & & .367 & .50 & .59 & 4.71 & .679 \\
\hline (26) You felt discriminated because of your race or ethnicity & & & & .364 & .49 & .60 & 4.65 & .760 \\
\hline (27) Your doctor made assumptions about your level of education & & & & .484 & .33 & .39 & 4.81 & .599 \\
\hline (28) Your doctor made assumptions about your income & & & & .497 & .35 & .31 & 4.92 & .393 \\
\hline (29) Your doctor made assumptions about your use of alcohol or drugs & & & & .679 & .04 & deleted & 4.60 & .827 \\
\hline 2. Diabetes patient self-efficacy & Cronbach's & Items & Valid & Cronbach's $\alpha$ if Item & Original Item-Total & Revised Item-Total & Mean & SD \\
\hline Likert scales: 1-5 ( 1 =strongly disagree, $5=$ strongly agree) & $\alpha$ & $\mathrm{N}$ & cases & Deleted & Correlation & Correlation & & \\
\hline & 0.9 & 6 & 142 & & & & & \\
\hline (30) You believe you know the positive ways you cope with diabetes-related s & tress & & & .858 & .48 & .47 & 3.69 & 1.012 \\
\hline (31) You can maintain the changes in your health habits like diet, exercise, e & ven during tin & mes of $s$ & tress & .909 & .13 & deleted & 3.18 & 1.102 \\
\hline $\begin{array}{l}\text { (32) You believe you know enough about yourself as a person to make diabete } \\
\text { for you }\end{array}$ & es care choice & e that at & re right & .813 & .79 & .79 & 3.92 & .978 \\
\hline (33) You believe you can ask for support for caring for your diabetes when you & u need & & & .823 & .72 & .76 & 4.08 & .964 \\
\hline (34) You believe you are able to turn your diabetes goals into a workable plar & & & & .812 & .79 & .83 & 3.98 & .985 \\
\hline (35) You can try out different ways of overcoming barriers to your diabetes go & als & & & .814 & .80 & .83 & 3.98 & .895 \\
\hline (36) You know what helps you stay motivated to care for your diabetes & & & & .813 & .79 & .83 & 3.98 & .964 \\
\hline
\end{tabular}


Table 6 Convergent validity and discriminant validity of the revised survey

\begin{tabular}{|c|c|c|c|c|c|c|c|c|c|}
\hline \multirow[t]{3}{*}{ Main Scales } & \multirow[t]{3}{*}{ Items $(\mathrm{N})$} & \multirow{2}{*}{\multicolumn{2}{|c|}{ Convergent Validity }} & \multicolumn{6}{|c|}{ Discriminant Validity } \\
\hline & & & & \multirow[t]{2}{*}{$\sqrt{\text { AVVE }}$} & \multicolumn{5}{|c|}{ Scale Correlation Matrix } \\
\hline & & $\mathrm{AVE}$ & $\overline{\mathrm{CR}}$ & & 1 & 2 & 3 & 4 & 5 \\
\hline 1. Interpersonal communication/ Interpersonal Relationship & 12 & 0.7 & 0.99 & 0.82 & & 0.46 & 0.63 & 0.26 & 0.01 \\
\hline 2. $\quad$ Patient-centred decision making & 4 & 0.6 & 0.88 & 0.80 & 0.46 & & 0.47 & 0.17 & 0.06 \\
\hline 3. Holistic/continuing care with cultural Competence & 8 & 0.4 & 0.86 & 0.66 & 0.63 & 0.47 & & 0.21 & -0.08 \\
\hline 4. Social sensitivity (Discrimination) & 4 & 0.5 & 0.78 & 0.69 & 0.26 & 0.17 & 0.21 & & -0.11 \\
\hline 5. $\quad$ Patient self efficacy & 6 & 0.7 & 0.94 & 0.85 & 0.01 & 0.06 & -0.08 & -0.11 & \\
\hline
\end{tabular}

Notes. AVE value $>0.5 ; \mathrm{CR}$ value $>0.5$.

Table 7 Scale descriptive statistics of the revised Indigenous Diabetic Patient Experience Survey (34 items)

\begin{tabular}{|c|c|c|c|c|c|c|c|c|}
\hline \multicolumn{2}{|c|}{$\begin{array}{c}\text { Scale Descriptive } \\
\text { Features }\end{array}$} & \multicolumn{2}{|c|}{ Interpersonal communication/ relationship } & \multirow[t]{2}{*}{$\begin{array}{l}\text { Patient-centred decision } \\
\text { making }\end{array}$} & \multicolumn{2}{|c|}{$\begin{array}{l}\text { Holistic/continuous care with cultural } \\
\text { competence }\end{array}$} & \multirow{2}{*}{$\begin{array}{c}\text { Social } \\
\text { sensitivity } \\
\text { (Discrimination) }\end{array}$} & \multirow[t]{2}{*}{$\begin{array}{l}\text { Diabetes patient self- } \\
\text { efficacy }\end{array}$} \\
\hline \multicolumn{2}{|l|}{$N=154$} & $\begin{array}{c}\text { Interpersonal } \\
\text { communication }\end{array}$ & $\begin{array}{l}\text { Interpersonal } \\
\text { relationship }\end{array}$ & & $\begin{array}{l}\text { Holistic/ continuing } \\
\text { care }\end{array}$ & $\begin{array}{c}\text { Cultural } \\
\text { competence }\end{array}$ & & \\
\hline \multicolumn{2}{|l|}{ Mean } & 4.20 & 3.15 & 3.14 & 3.24 & 3.72 & 4.77 & 3.93 \\
\hline \multicolumn{2}{|l|}{ Median } & 4.33 & 3.33 & 3.25 & 3.20 & 4.00 & 5.00 & 4.00 \\
\hline \multicolumn{2}{|c|}{ Std. Deviation } & .758 & .657 & .693 & 1.091 & 1.071 & .445 & .793 \\
\hline \multicolumn{2}{|l|}{ Kurtosis } & .436 & .534 & .234 & -.878 & -.117 & 4.849 & 3.693 \\
\hline \multicolumn{2}{|l|}{ Range } & $2-5$ & $1-4$ & $1-4$ & $1-5$ & $1-5$ & $3-5$ & $1-5$ \\
\hline \multirow[t]{3}{*}{ Percentiles } & 25 & 3.89 & 2.67 & 2.75 & 2.40 & 3.00 & 4.75 & 3.50 \\
\hline & 50 & 4.33 & 3.33 & 3.25 & 3.20 & 4.00 & 5.00 & 4.00 \\
\hline & 75 & 4.89 & 3.67 & 3.75 & 4.20 & 4.67 & 5.00 & 4.42 \\
\hline
\end{tabular}

\section{Figures}

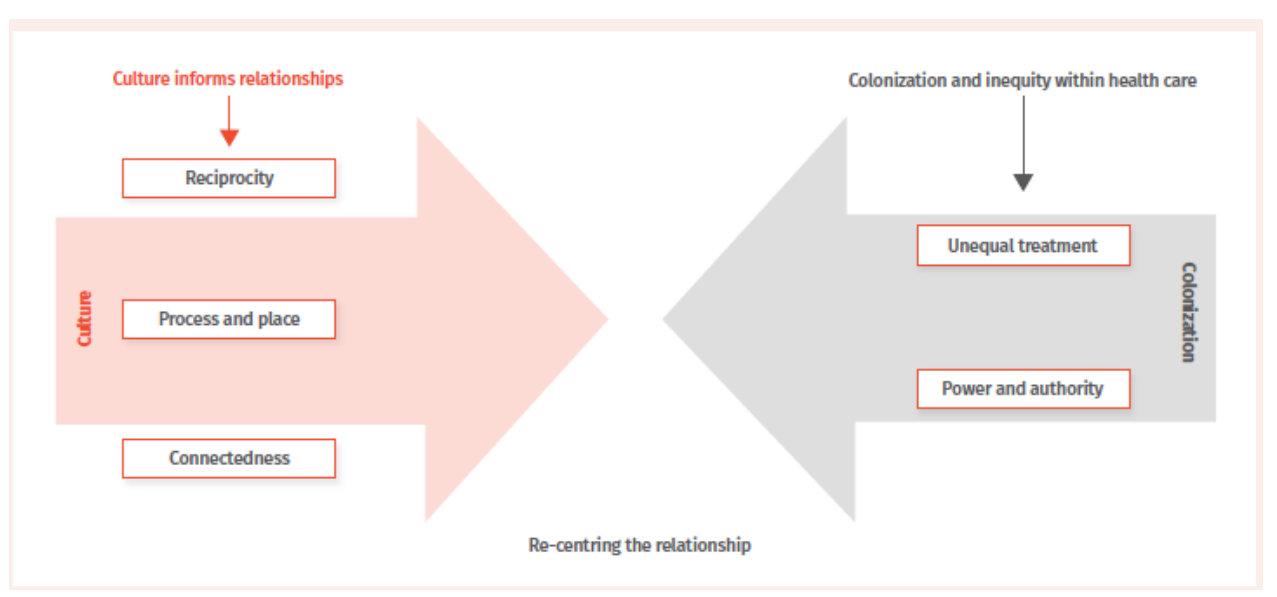

\section{Figure 1}

The E4E Care Framework reveals social and economic resource disparities experienced by Indigenous people and provides two directives for clinicians in providing care, namely: 1) re-center clinical relationships (e.g., address power and authority), and 2) engage with patient social realities (e.g., social barriers, cultural facilitators) as opportunities for change. Each directive is grounded in cultural facilitators for addressing critical social variables arising from the legacy of colonization, which impact both the patient's world and healthcare relationships.

\section{Supplementary Files}

This is a list of supplementary files associated with this preprint. Click to download.

- Appendix1Likertscalespatientexperiencesurvey.docx 